\title{
Research on the Creep Characteristics of Thermal Insulation Shotcrete under the Action of Temperature and Humidity Circulation
}

\author{
Jinsong Zhang $\mathbb{D},{ }^{1,2}$ Yaxing Wang $\mathbb{D}^{2},{ }^{2}$ Junjun Liu $\mathbb{D},{ }^{2}$ and Jiuqun Zou $\mathbb{C}^{2}$ \\ ${ }^{1}$ State Key Laboratory of Mining Response and Disaster Prevention and Control in Deep Coal Mine, \\ Anhui University of Science and Technology, Anhui, Huainan 232000, China \\ ${ }^{2}$ School of Civil Engineering and Architecture, Anhui University of Science and Technology, Anhui, Huainan 232000, China
}

Correspondence should be addressed to Jiuqun Zou; jqzou1225@sina.com

Received 25 April 2021; Revised 29 July 2021; Accepted 13 August 2021; Published 19 August 2021

Academic Editor: Guoming Liu

Copyright (C) 2021 Jinsong Zhang et al. This is an open access article distributed under the Creative Commons Attribution License, which permits unrestricted use, distribution, and reproduction in any medium, provided the original work is properly cited.

In order to explore the creep characteristics of thermal insulation shotcrete under the action of temperature and humidity circulation, a series of uniaxial compression creep tests were carried out with different cycles of temperature and humidity and hierarchical loading conditions. The test results show that the axial creep deformation and creep strain of the thermal insulation shotcrete specimens increase with the increase of the number of drying and wetting cycles under normal temperature water bath condition. After 28 cycles, the deformation value becomes larger obviously, and the creep strain increases greatly in the precycle period. The thermal insulation shotcrete axial steady-state creep rate increases nonlinearly with the increase of the number of drying and wetting cycles under different stress levels. When the number of adjacent cycles is $0-3$, the average increase is larger, and the axial steady-state creep rate of thermal insulation shotcrete for 28 cycles increases with the increase of water bath temperature. The instantaneous deformation modulus of thermal insulation shotcrete decreases logarithmically with the increase of the number of drying and wetting cycles, and the total deterioration degree of the average instantaneous deformation modulus increases gradually, but the deterioration degree between adjacent cycles decreases successively. The thermal insulation shotcrete specimens with 3 cycles of fracture were mainly stretched, and with the increase of the water bath temperature, the specimen was damaged by shear failure. When the water bath temperature is $40^{\circ} \mathrm{C}$, the fracture degree of the specimen increases first and then decreases with the increase of the number of cycles.

\section{Introduction}

Nowadays, some practical projects often face high-temperature damage problems $[1,2]$, such as the environment in which certain roadways are located in the process of coal mining. Solving the temperature problems encountered in the project is of practical significance to improving the project environment. Zhang and Xiao-Qiang [3] used inorganic sprayed concrete materials as the insulation layer and developed high-performance heat-insulating lightweight aggregate sprayed concrete that can be applied in different rock temperature environments. Yao and Pang [4] selected a variety of thermal insulation materials, and a new type of thermal insulation concrete was obtained through a cross test, which found a good thermal insulation effect that its thermal conductivity was only $1 / 8$ of that of ordinary concrete, At present, there have been more and more research studies on insulated shotcrete (HS), and exploring the relevant characteristics of HS has certain theoretical value. In some roadway excavation projects, HS as the sprayed layer of the roadway will change the moisture content of the surrounding rock due to various effects [5-8] and the changes of temperature stress [9], and the ventilation situation in the roadway may cause the insulated sprayed concrete to be at the state of alternation of wetting and drying; in the indoor test, dry and water bath alternate treatments are performed on the sample to simulate the dry-wet cycles process. Regarding the dry-wet cycles of concrete, domestic and foreign 
scholars have conducted a lot of research studies in recent years. Zhao Gao-wen et al. [10] found that the underground cast-in-situ concrete structure often suffers from multiple ion dry and wet alternate compound erosion. The indoor test conditions are used to simulate the compound erosion process of underground cast-in-place concrete structures in actual projects. The size, quality, and compressive strength changes of the specimens and the distribution of sulfate at different depths were measured. Li Bei-xing et al. [11] carried out the semi-immersion dry-wet cycles test of three kinds of concrete with large amount of mineral admixture in sodium sulfate solution, which studied the chemical corrosion damage mechanism of concrete and the role of mineral admixture in it. Chen Wei-Kang and Liu [12] systematically studied the coupling transmission process of moisture and polyions in concrete under alternating wet and dry conditions. Zhang and Sun [13] used drying and wetting cycles and full immersion methods to carry out $\mathrm{Cl}^{-1}$ permeation comparison tests, which found that the dry-wet cycles accelerate the migration of $\mathrm{Cl}^{-1}$ into the concrete. Yao et al. [14] studied the influence of the chloride dry-wet cycles on the average shear strength and slip at the interface between fiber braid-mesh reinforced concrete (TRC) and existing concrete through double-sided shear test. The test results show that with the increase of the number of chloride salt drying and wetting cycles, the interface performance between TRC and existing concrete decreases. Xue-Qiang et al. [15] explored the effect of drying and wetting cycles on the resistance of concrete to chloride ion penetration. It was found that the effect of dry-wet cycles roughened the surface pore structure of concrete specimens, increased the pore content of pore diameters $>50 \mathrm{~nm}$, and significantly increased the free and total chloride ion concentration. Jiang and Di-Tao [16] obtained the full stress-strain curve equation under uniaxial compression through the action of concrete sulfate erosion and dry-wet cycles and found a method to determine the damage layer concrete stress-strain equation. Chen et al. [17] used NMR technology to collect T2 spectrum and porosity under different wetting and drying cycles, analyzed the pore development and porosity change under wetting and drying cycles tests, and obtained the damage rule of recycled concrete under wetting and drying cycles environment. Yue et al. [18] studied the porosity, ultrasonic sound velocity, and compressive strength of concrete specimens with different numbers of drying and wetting cycles. Jiang Shao-fei et al. [19] carried out the corrosion degradation test of concrete's elastic modulus, compressive strength, and CFRP-concrete shear specimen interface bond performance under different dry-wet cycles. Qiang et al. [20] presented the physical and mechanical characteristics of AAS mortars (i.e., visual appearance, compressive/flexural strength, mass change, capillary porosity, and water sorptivity), as well as mineralogical and chemical parameters were determined using XRD, FTIR, DSC, and BSE. Findings were compared to Portland cement (PC) and high sulfate resistant (HSR) samples. Guo et al. [21] The results show that with the prolongation of the dry-wet cycles, the deterioration degree of concrete increases first and then decreases. The microstructure analysis shows that the corrosion depth of sulfate erosion increases with the increase of dry-wet cycles. Dehestani et al.' [22] experimental study found that as the number of wet and dry cycles increases, the tensile and shear fracture toughness of concrete decreases. Daqing et al. [23] studied the relationship between compressive strength and splitting strength of recycled concrete under the action of dry-wet cycles. Cao et al.' [24] experimental results show that compared with the conditions of long-term immersion in water, the wetting and drying cycles will significantly increase the creep deformation of the axial compressive fly ash concrete members, mainly in the early four dry-wet cycles.

There are many studies on the relevant properties of concrete under different dry-wet cycles. Many scholars have mainly studied the compressive, tensile strength, and antipermeability properties of samples under different dry-wet cycles. However, concrete is often subjected to the long-term effect of external stress in some projects, so the study of the creep characteristics of concrete samples after different drywet cycles has practical significance for the long-term strength evaluation of concrete in some projects. Furthermore, due to the increase in temperature of some projects [25], the study of the changes in the creep mechanical properties of concrete samples after different water bath temperature treatments and different dry-wet cycles has provided the theoretical reference value for concrete engineering to a certain extent.

In order to better study the creep characteristics of concrete under different water bath temperatures and different dry-wet cycles, this study takes HS as the research object and uses the RDL-200 electronic creep relaxation tester to test samples after different water bath temperatures and dry-wet cycles. The uniaxial compression creep test was carried out to study the influence of different dry-wet cycles and different water bath temperatures on the relative creep mechanical properties of HS and revealed the mechanism of the impact of different dry-wet cycles and water bath temperatures on HS.

\section{The Design of the Temperature and Humidity Cycles Test}

2.1. Test Instrument. In this test, the water bath process of specimens should be carried out in the digital constant temperature circulating water tank $\mathrm{HH}-420$, and the temperature control range is room temperature to $100^{\circ} \mathrm{C}$, as shown in Figure 1(a); the drying process should be carried out in the DHG constant temperature drying oven, and the temperature control range is $10-300^{\circ} \mathrm{C}$, as shown in Figure 1(b). The creep test should use the RDL-200 electronic creep relaxation tester, the test force measurement error is not more than $\pm 0.5 \%$ of the indicated value, and the deformation measurement range is $0-10 \mathrm{~mm}$. The resolution is $0.001 \mathrm{~mm}$, as shown in Figure 1(c).

2.2. Mixture Ratio Design. The raw materials for the test are selected as follows according to the specification [26]: the sand is fine sand, the stone is Huainan melon seed slices 


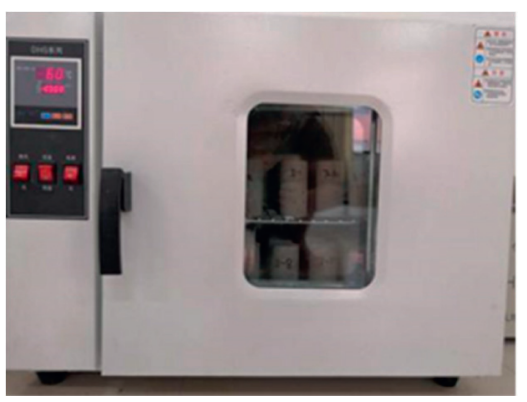

(a)

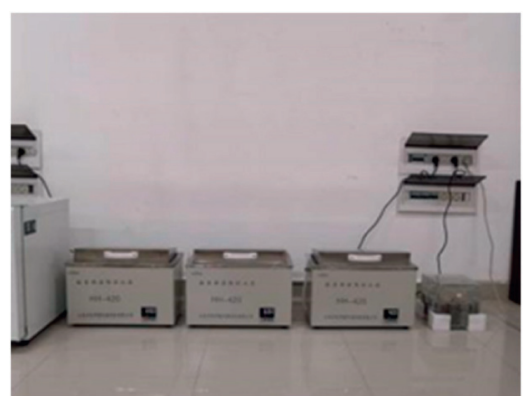

(b)

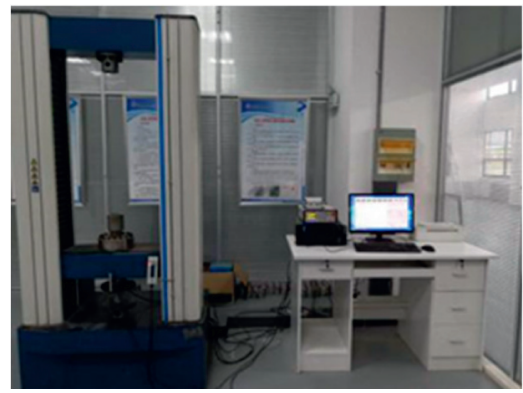

(c)

Figure 1: Test apparatus. (a) HH-420 constant temperature circulating water tank. (b) DHG constant temperature drying oven. (c) RDL series electronic creep relaxation test.

stone of $5-10 \mathrm{~mm}$, and cement is P.O42.5 ordinary Portland cement produced in Bagongshan, Huainan, the fly ash is grade I fly ash, and the mixing water is tap water. The optimum mix proportion is calculated according to grey correlation degree from the previous 9 groups of specimens, as given in Table 1.

2.3. Specimen Making. According to the specification [27], the test should use the mold with the size of $\varphi$ $50 \mathrm{~mm} * 100 \mathrm{~mm}$, then put the mode into the saturated $\mathrm{Ca}(\mathrm{OH})_{2}$ solution for curing for 28 days, and then take it out and grind the rough end face, as shown in Figure 2.

2.4. Test Scheme. The thermal insulation shotcrete specimen was dried in the drying box for $8 \mathrm{~h}$, took out and cooled for $30 \mathrm{~min}$, and then put into the constant temperature water bath box for water bath for $16 \mathrm{~h}$, which was a dry-wet cycle. The temperature of the first drying of the specimen should be $105^{\circ} \mathrm{C}$, and the later drying temperature should be $60^{\circ} \mathrm{C}$. The so-called temperature and humidity cycles are the process of specimen cycling in different water bath temperatures. The specimens were divided into four groups and placed in four different water bath temperatures of room temperature, $40^{\circ} \mathrm{C}, 60^{\circ} \mathrm{C}$, and $80^{\circ} \mathrm{C}$ for circulation. Each group of 12 blocks underwent $3,7,14$, and 28 times of dry-wet cycles, respectively. After the end of the cycle, prevent contact with air, seal, and store for the next step of the test. The specific steps are shown in Figure 3. The creep test is carried out by step loading, and the creep loading value is determined by the average value of uniaxial compressive strength after the specimen reaches the curing age. Taking $40 \%$ of the compressive strength as the initial stress value, the step loading is divided into five stages. The stress increment of each stage is $2.598 \mathrm{MPa}$, the stress duration of each stage is $12 \mathrm{~h}$, the data acquisition interval is $5 \mathrm{~s}$ during loading, and the acquisition interval for stress holding is $10 \mathrm{~min}$. The specific axial graded stress is given in Table 2, The specific test scheme is given in Table 3.

\section{The Results and Analysis of the Creep Test}

Thanks to the internal heterogeneity of concrete specimens, and the grading stress value is determined according to the average value of compressive strength of several specimens; so when the axial graded stress exceeds the compressive strength of the specimen itself, the specimen will experience creep failure, and its deformation will change greatly when compared with the deformation under other stresses. Therefore, only the influences of the first four stages of temperature and humidity cycles on the axial strain, axial creep strain, steady creep rate, and instantaneous deformation modulus of thermal insulation concrete are studied.

3.1. Analysis of Creep Characteristics of Specimens under Different Dry-Wet Cycles. The creep curve of HS specimen with different drying and wetting cycles under normal temperature water bath is shown in Figure 4.

3.1.1. Creep Curve Analysis of Samples with Different Dry-Wet Cycles. The results show that the axial strain of thermal insulation shotcrete specimen increases with the increase of loading stages. The instantaneous deformation occurs at the moment of stress loading, and creep occurs when the stress is constant. The slope of early creep curve gradually decreases with time, showing deceleration creep, and then, the slope of curve basically tends to be a constant value, showing steady-state creep. As shown in Figure 4, the instantaneous deformation and creep deformation of thermal insulation shotcrete specimen increase with the increasing times of the dry and wet cycles, and the deformation values after cycling for 28 times increase obviously.

3.1.2. Effect of Dry-Wet Cycles on Axial Creep Strain of Specimens. The change of axial creep strain of thermal insulation shotcrete under different stress levels and cycle times is shown in Figure 5. It can be seen from the figure that the axial creep strain changing rule of thermal insulation shotcrete is basically the same under different stress levels, and the axial creep strain increases with the increasing times of the drying and wetting cycles. The results show that the axial creep strain is larger under the first-order stress and high stress level. The reason is that the compactness of the concrete itself is poor for manufacture factors; thus, the inside of the concrete itself exist cracks. The crack shrinks 
TABLE 1: Mixture ratio of specimen $\left(\mathrm{kg} / \mathrm{m}^{3}\right)$.

\begin{tabular}{|c|c|c|c|c|c|c|c|c|c|c|}
\hline Ceramsite & Taunsa & Basalt fiber & Plant fiber & Vitrified microsphere & Sand & Gravel & Cement & Fly ash & Water-reducing agent & Water \\
\hline 58.142 & 66.448 & 5.26 & 0.4 & 9 & 764.152 & 772.458 & 427.5 & 47.5 & 3.8 & 213.8 \\
\hline
\end{tabular}

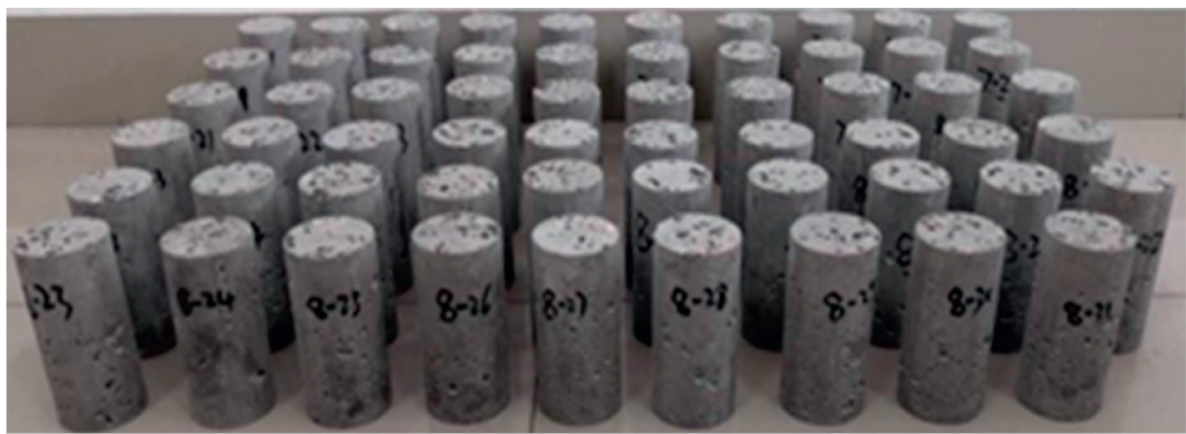

FIGURE 2: Concrete specimen.

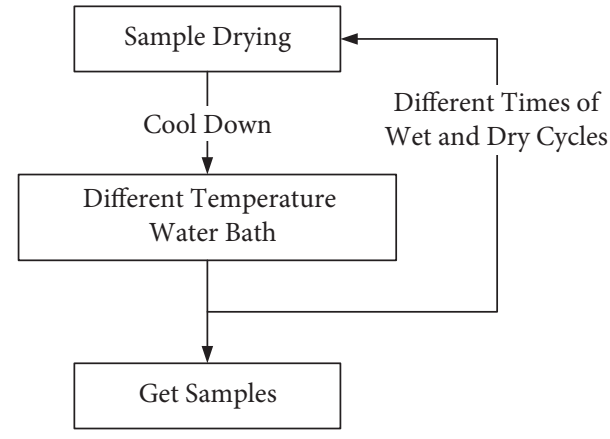

FIGURE 3: Sample preparation step diagram.

under the primary stress; thus, the axial creep strain becomes larger, and the high stress accelerates the shrink of the crack.

In order to make the change of axial creep strain of thermal insulation shotcrete more specific, the average increment [28] is introduced. The formula of the average increment of thermal insulation shotcrete axial creep strain under adjacent drying and wetting cycles could be expressed as follows:

$$
\Delta \varepsilon=\frac{\left(\varepsilon_{n}-\varepsilon_{m}\right) / \varepsilon_{m}}{n-m} \times 100 \% .
$$

In the formula, $\varepsilon_{n}$ and $\varepsilon_{m}$ represent the axial creep strain after doing $n$ times and $m$ times of thermal insulation shotcrete drying and wetting cycles, respectively. When $n$ is $3,7,14$, and 28 , the value of $M$ is $0,3,7$, and 14 .

The average increment table of thermal insulation shotcrete axial creep strain under adjacent drying and wetting cycles (Table 4) is given. It can be found that the average increase of axial creep strain of thermal insulation shotcrete under $0-3$ and 3-7 cycles is significantly higher than that under 7-14 and 14-28 cycles. The maximum increase of axial creep strain at $0-3$ times is $16.21 \%$, and the minimum value of $8.26 \%$ under $0-3$ and $3-7$ cycles is much higher than the maximum value of the average increase under 7-14 and 14-28 cycles. This indicates that the axial creep strain of thermal insulation shotcrete increases greatly in the early stage of the drying and wetting cycles.

3.1.3. The Effect of the Drying and Wetting Cycles on Axial Steady Creep Rate of Thermal Insulation Shotcrete for Sample. The changing chart of thermal insulation shotcrete axial steady creep rate under different stress levels in different dry and wet cycles is shown in Figure 6. It can be found that the changing trend of thermal insulation shotcrete axial steady-state creep rate under different stress levels is basically the same as the changing of the times of the drying and wetting cycles. It is all increases nonlinearly with the increasing times of the dry and wet cycles, and the axial steady-state creep strain rate value under the higher stress level is much higher. The average increase of thermal insulation shotcrete axial steady-state creep rate under adjacent drying and wetting cycles is given in Table 5 . The table provides that the average increase of axial steady-state creep rate under adjacent drying and wetting cycles is quite different, among which the average increase of $0-3$ times is the largest, and the maximum value is $92.57 \%$, which is far more than the average increase value of other adjacent cycles. This indicates that the axial steady creep rate of thermal insulation shotcrete increases greatly at $0-3$ times of adjacent cycles.

3.1.4. Effect of Dry-Wet Cycles on Instantaneous Deformation Modulus of Samples. The ratio of each step stress to its corresponding instantaneous strain is defined as the instantaneous deformation modulus of thermal insulation shotcrete, $E_{0}$. Taking the number of drying and wetting cycles, $n$ as the abscissa and the instantaneous deformation modulus under each cycle number as the ordinate, the scatter distribution diagram of instantaneous deformation modulus under different stress levels after drying and wetting cycles for $0,3,7,14$, and 28 times was drawn. After fitting it with the logarithmic function, the fitting results are 
TABLE 2: Axial graded stress.

\begin{tabular}{|c|c|c|c|c|c|}
\hline \multirow{2}{*}{ Loading series } & \multicolumn{5}{|c|}{ Axial graded stress $(\mathrm{MPa})$} \\
\hline & 0 & 3 & 7 & 14 & 28 \\
\hline 1 & 6.926 & 6.926 & 6.926 & 6.926 & 6.926 \\
\hline 2 & 9.524 & 9.524 & 9.524 & 9.524 & 9.524 \\
\hline 3 & 12.121 & 12.121 & 12.121 & 12.121 & 12.121 \\
\hline 4 & 14.719 & 14.719 & 14.719 & 14.719 & 14.719 \\
\hline 5 & 17.316 & 17.316 & 17.316 & 17.316 & 17.316 \\
\hline
\end{tabular}

TABle 3: Specific test plan.

\begin{tabular}{lcccc}
\hline \multirow{2}{*}{ Times } & \multicolumn{3}{c}{$T\left({ }^{\circ} \mathrm{C}\right)$} \\
& 25 & 40 & 60 & \\
\hline \multirow{4}{*}{3} & $\mathrm{~A} 11 / 7-24$ & & & \\
& $\mathrm{~A} 12 / 7-26$ & & & \\
& $\mathrm{~A} 13 / 7-4$ & & & \\
\hline \multirow{5}{*}{7} & $\mathrm{~A} 21 / 7-10$ & & \\
& $\mathrm{~A} 22 / 8-4$ & & & \\
\hline \multirow{4}{*}{14} & $\mathrm{~A} 23 / 8-2$ & & & \\
& $\mathrm{~A} 31 / 8-12$ & & & \\
& $\mathrm{~A} 32 / 8-3$ & & & \\
& $\mathrm{~A} 33 / 8-29$ & & & \\
28 & $\mathrm{~A} 41 / 7-18$ & $\mathrm{~B} 41 / 8-1 / 8-7$ & \\
& $\mathrm{~A} 42 / 8-17$ & $\mathrm{~B} 42 / 8-19$ & $\mathrm{C} 42 / 8-30$ & $\mathrm{D} 42 / 8-16$ \\
& $\mathrm{~A} 43 / 8-26$ & $\mathrm{~B} 43 / 8-20$ & $\mathrm{C} 43 / 8-24$ & $\mathrm{D} 43 / 8-5$ \\
\hline
\end{tabular}

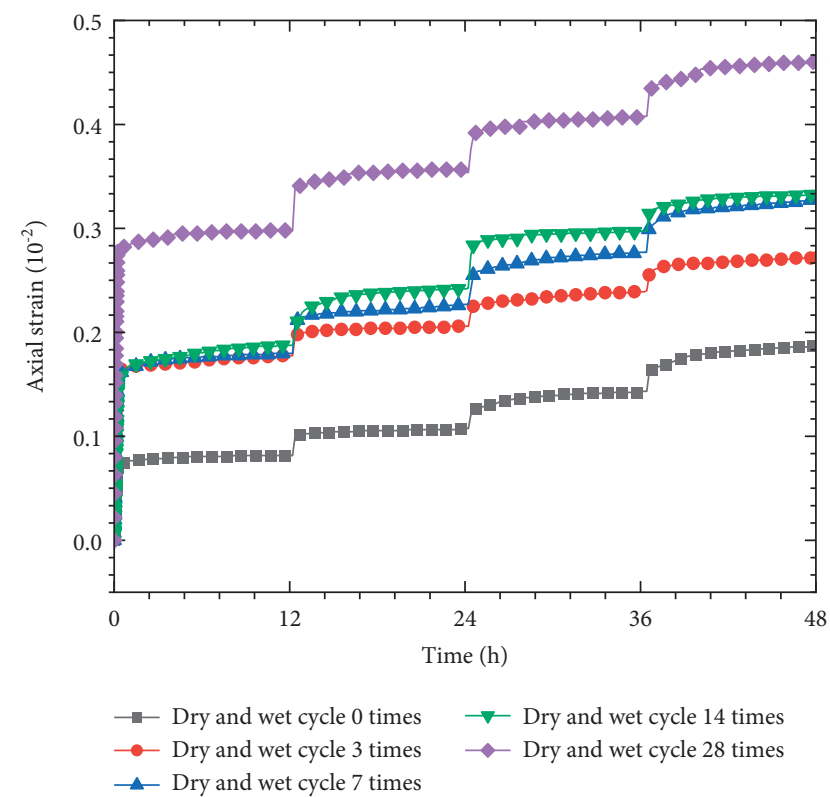

FIgURE 4: Uniaxial compression creep curve of different dry-wet cycles.

shown in Figure 7. As shown in the figure, the instantaneous deformation modulus of thermal insulation shotcrete decreases nonlinearly with the increasing times of the drying and wetting cycles. What is more, the instantaneous deformation modulus of thermal insulation shotcrete $E_{0}$ at different stress levels has the following relationship with the times of drying and wetting cycles, $n$ :

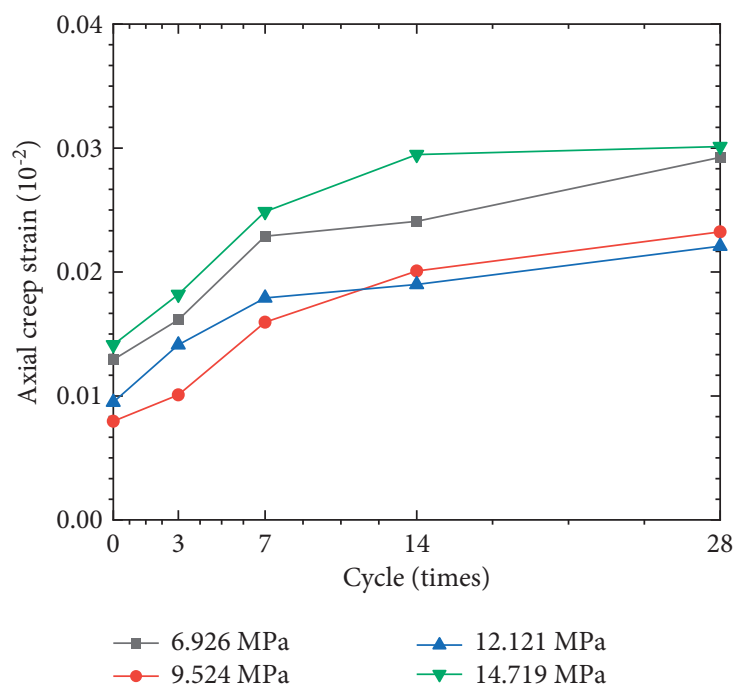

Figure 5: Axial creep strain of thermal insulation shotcrete under different drying and wetting cycles.

$$
E_{0}=6.31-0.86 \ln n\left(R^{2}=0.95\right) .
$$

The instantaneous elastic modulus of thermal insulation shotcrete at different stress levels fluctuates in a certain range under the same cycle times. Therefore, the average value of instantaneous elastic modulus under four stress levels was taken as the research object to explore the variation of instantaneous elastic modulus of thermal insulation shotcrete under different wetting and drying cycles. According to the research of Deng [29], define the decreases of degree of the average instantaneous deformation modulus of thermal insulation shotcrete after different drying and wetting cycles as degradation degree and define the average decrease degree of thermal insulation shotcrete average instantaneous deformation modulus as the stage degradation degree $\Delta s$. Thus, the relationship of total degradation degree $\mathrm{Sn}$ and stage deterioration degree $\Delta s$ can be expressed as follows:

$$
\begin{aligned}
S_{n} & =\frac{\overline{E_{00}}-\overline{\mathrm{E}_{0 \mathrm{n}}}}{\overline{E_{00}}} \times 100 \%, \\
\Delta S & =\frac{S_{n}-S_{m}}{n-m} .
\end{aligned}
$$

In the formula, $\overline{E_{00}}$ is the average value of the instantaneous deformation modulus of the sample when the drywet cycles is 0 times, and $\overline{E_{0 n}}$ is the average value of the 
TавLE 4: Average increment of thermal insulation shotcrete axial creep strain under adjacent drying and wetting cycles.

\begin{tabular}{lcccc}
\hline Stress level (MPa) & \multicolumn{3}{c}{ Average increment of axial creep strain (\%) } \\
\hline 6.926 & $0-3$ & $3-7$ & $7-14$ & $14-28$ \\
9.524 & 8.26 & 10.46 & 0.75 & 1.53 \\
12.121 & 8.92 & 14.52 & 3.70 & 1.12 \\
14.719 & 16.21 & 6.71 & 0.87 & 1.16 \\
\hline
\end{tabular}

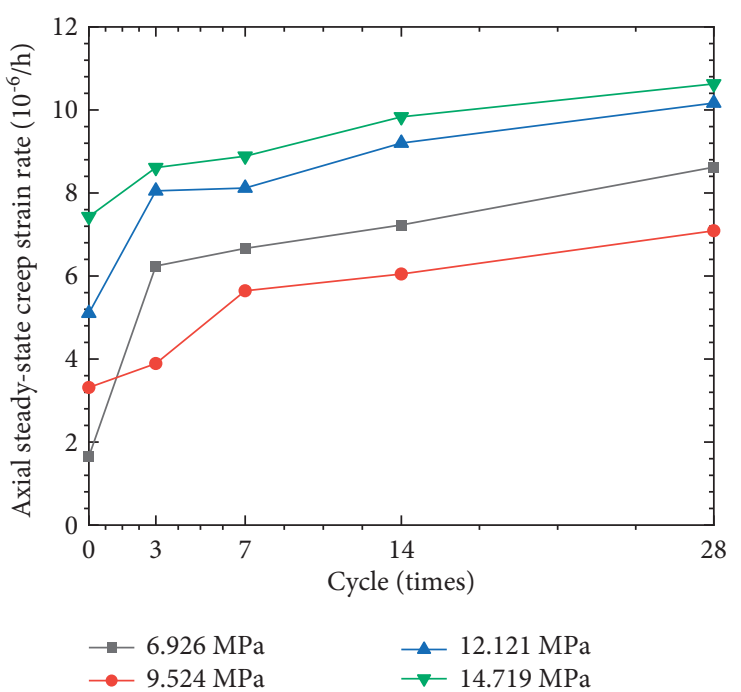

Figure 6: Axial steady creep rate of thermal insulation shotcrete under different drying and wetting cycles.

instantaneous deformation modulus of the sample during $N$ dry-wet cycles. When $n$ is $3,7,14$, and $28, M$ is $0,3,7$, and 14 .

According to the calculation results of equations (3) and (4), the total deterioration degree $S_{n}$ and the stage deterioration degree $\Delta s$ of thermal insulation shotcrete average instantaneous deformation modulus under different drying and wetting cycles are planted (Figure 8). As shown in Figure 8 , with the increasing times of the drying and wetting cycles, the total deterioration degree of average instantaneous deformation modulus gradually increases, and their value are $44.81 \%, 51.24 \%, 57.33 \%$, and $65.05 \%$ (from small to large). But the stage deterioration degree between $0,3,7,14$, and 28 adjacent cycle times decreases in turn, of which the deterioration degree of $0-3$ times is the largest, reaching $14.94 \%$, which is far greater than that of other adjacent cycle times. This indicates that the deterioration of thermal insulation shotcrete is gradual processing during the drying and wetting cycles. What is more, during the process of drying and reabsorbing water at the early stage of the cycle, there is a large concentration gradient difference between the surface and the interior of the thermal insulation shotcrete specimen, which makes the deterioration degree obvious relatively.

\subsection{Creep Characteristics of Specimens at Different Water Bath} Temperatures. When the step stress is $14.719 \mathrm{MPa}$, the table of the axial steady-state creep rate of thermal insulation shotcrete at different water bath temperatures after experiencing drying
TABLE 5: Average increase of thermal insulation shotcrete axial steady creep rate under adjacent drying and wetting cycles times.

\begin{tabular}{lcccc}
\hline & \multicolumn{5}{c}{ Average increase of axial steady creep } \\
rate (\%)
\end{tabular}

and wetting for 28 times can be drawn as follows (Table 6). As it given in the table, the axial steady-state creep rate of thermal insulation shotcrete increases with the increase of water bath temperature, indicating that the drying and wetting cycles at higher water bath temperature will enhance the axial steadystate creep rate of thermal insulation shotcrete.

The logarithmic $\ln K$ is taken from the axial steady-state creep rate $K$ of thermal insulation shotcrete under different water bath temperatures, and logarithmic $\ln k$ has a linear relationship with the reciprocal $1 / T$ of the absolute temperature $T$, which can be analogically written as Arrhenius formula:

$$
K=A_{1} \exp \left(-\frac{Q_{C}}{R T}\right),
$$

where $K$ is the axial steady-state creep rate of specimen; $A_{1}$ is the material structure coefficient related to stress, and unit is consistent with $K ; R$ is the molar gas constant, which is $8.314 \mathrm{~J} /(\mathrm{mol} \cdot \mathrm{K})$; QC is the creep activation energy, unit: $\mathrm{J} /$ $\mathrm{mol} ; \mathrm{T}$ is the absolute temperature, unit: $\mathrm{K}$.

In the formula (5), the creep activation energy represents the energy required for a unit amount of material to creep initially. If the creep activation energy of the material is larger, it means that creep needs more energy; thus, it is difficult to produce creep under the same conditions. Therefore, the creep activation energy can be used to measure the deformation properties of materials.

If the logarithms of both sides of equation (5) are taken at the same time, then

$$
\ln K=\ln A_{1}-\frac{Q_{C}}{R T} .
$$

Fitting (Figure 9) according to the correlation value of formula (6) is given in Table 7.

The structural coefficient $A_{1}$ under the stress of 14.719 MPa was obtained by calculation. The creep activation energy QC obtained by fitting was $3.658 \mathrm{~kJ} / \mathrm{mol}$, and the correlation coefficient was 0.9744. As shown in Figure 9, the fitting results are good. 


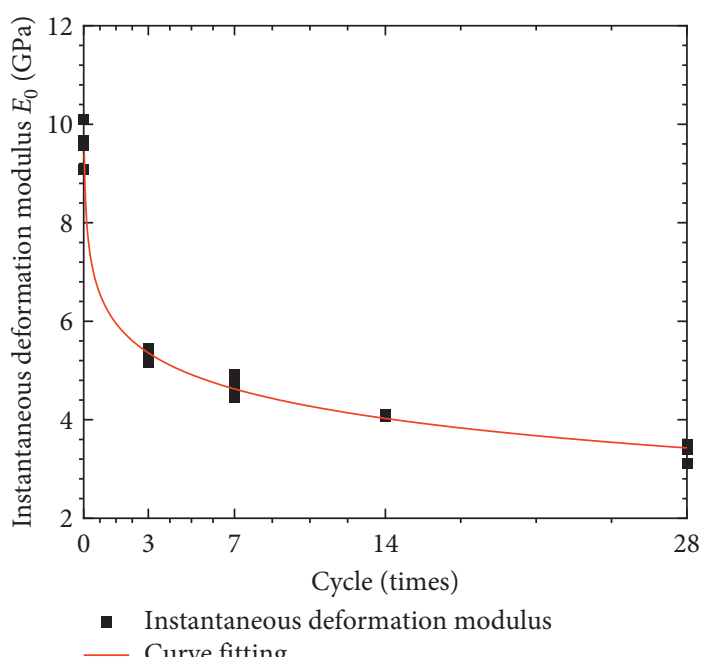

FIGURE 7: Fitting curves of thermal insulation shotcrete instantaneous deformation modulus under the drying and wetting cycles.

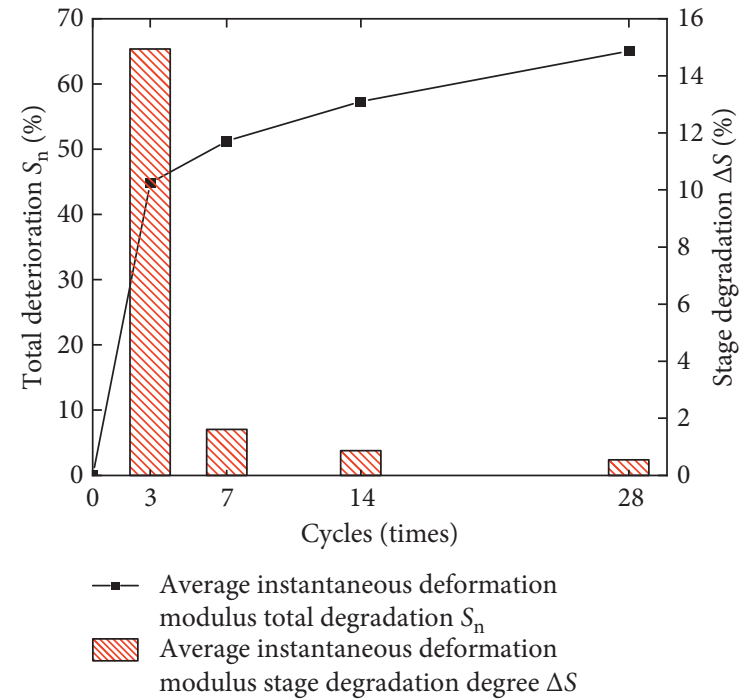

Figure 8: Total degradation degree and stage deterioration degree of average instantaneous deformation modulus under different drying and wetting cycles.

TABle 6: Axial steady-state creep rate at different water bath temperatures.

\begin{tabular}{lcccc}
\hline & \multicolumn{1}{c}{$\begin{array}{c}\text { Axial steady creep rate at different water bath } \\
\text { temperatures }\end{array}\left(10^{-6} / \mathrm{h}\right)$} & & \\
$\begin{array}{l}\text { Stress } \\
(\mathrm{MPa})\end{array}$ & $\begin{array}{c}\text { Normal atmospheric } \\
\text { temperature }\end{array}$ & $40^{\circ} \mathrm{C}$ & $60^{\circ} \mathrm{C}$ & $80^{\circ} \mathrm{C}$ \\
\hline 14.719 & 10.629 & 11.472 & 12.715 & 13.289 \\
\hline
\end{tabular}

\section{Failure Mode}

The uniaxial creep failure pattern of specimens under the action of temperature and humidity cycles is shown in Figures 10 and 11 . Figure 10 shows the failure pattern of specimens under the different water bath temperatures, and

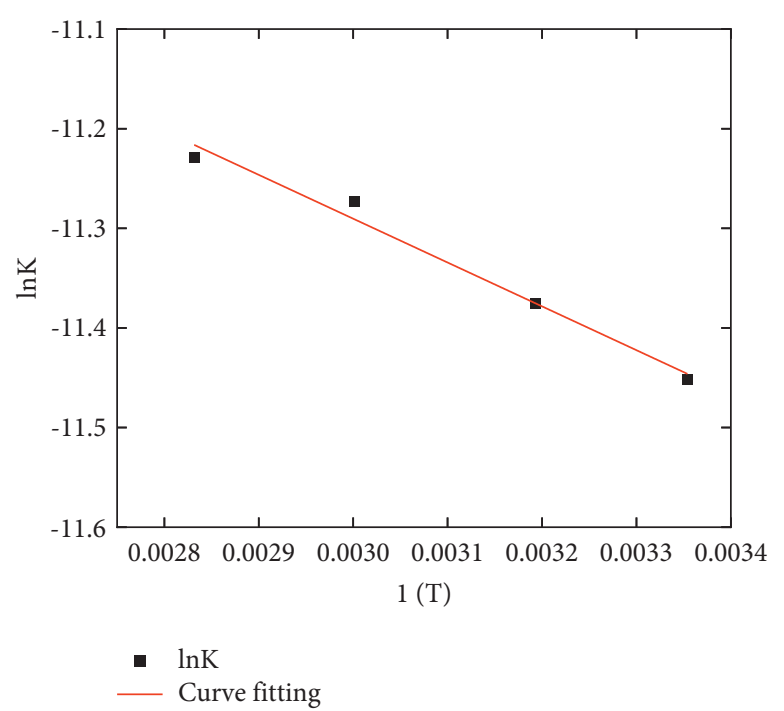

Figure 9: Fitting diagram of creep affected by water bath temperature.

Figure 11 shows the failure pattern of specimens under different cycles times under the same water bath temperature.

Under uniaxial conditions, the fracture of the specimen is mainly based on tensile. As shown in Figure 10, the fracture degree of the specimen decreases gradually. Under the action of low water bath temperature, the fracture of the specimen and the peripheral spalling part is more obvious. The main reason is that the internal matrix of the specimen may change under the action of temperature, and the fracture degree is getting lower and lower due to the closer connection of the matrix. What is more, with the increase of water bath temperature, shear failure appears. It can be seen from Figure 11 that when the water bath temperature is $40^{\circ} \mathrm{C}$, the fragmentation degree of the specimen first increases and then decreases with the increasing times of 
TABLE 7: Calculation table of creep fitting equation influenced by water bath temperature.

\begin{tabular}{|c|c|c|c|c|c|c|c|}
\hline $\begin{array}{l}\text { Stress } \\
(\mathrm{MPa})\end{array}$ & Temperature $\left({ }^{\circ} \mathrm{C}\right)$ & $\begin{array}{c}\text { Reciprocal of absolute } \\
\text { temperature }(1 / \mathrm{K})\end{array}$ & $\begin{array}{c}\text { Axial steady-state } \\
\text { creep rate } K\left(10^{-6} / \mathrm{h}\right)\end{array}$ & $\operatorname{Ln} K$ & Fitting & $\begin{array}{c}A_{1} \\
\left(10^{-11} / \mathrm{h}\right)\end{array}$ & $\begin{array}{c}Q_{C}(\mathrm{~kJ} / \\
\mathrm{mol})\end{array}$ \\
\hline \multirow{4}{*}{14.72} & $\begin{array}{c}\text { Normal atmospheric } \\
\text { temperature }\end{array}$ & 0.003354 & 10.6294 & -11.452 & \multirow{4}{*}{$y=-439.97 x-9.97$} & \multirow{4}{*}{4.68} & \multirow{4}{*}{3.658} \\
\hline & 40 & 0.003193 & 11.4717 & -11.376 & & & \\
\hline & 60 & 0.003002 & 12.7148 & -11.273 & & & \\
\hline & 80 & 0.002832 & 13.2894 & -11.229 & & & \\
\hline
\end{tabular}

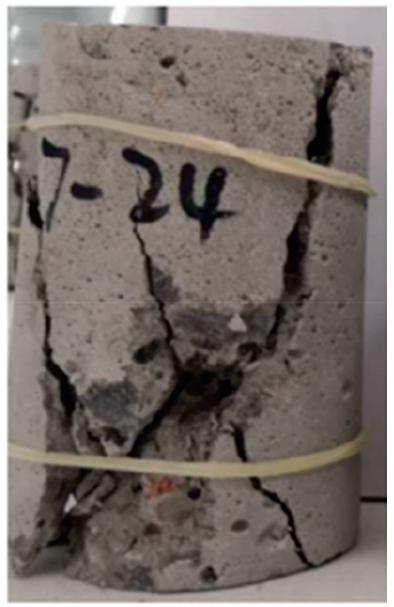

(a)

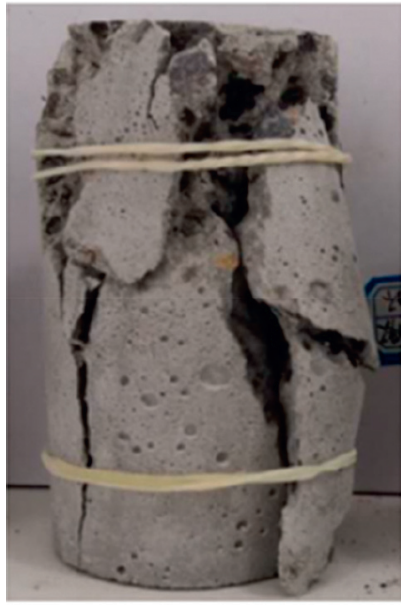

(b)

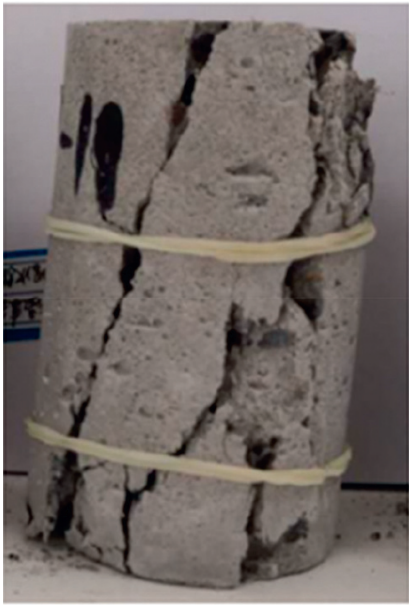

(c)

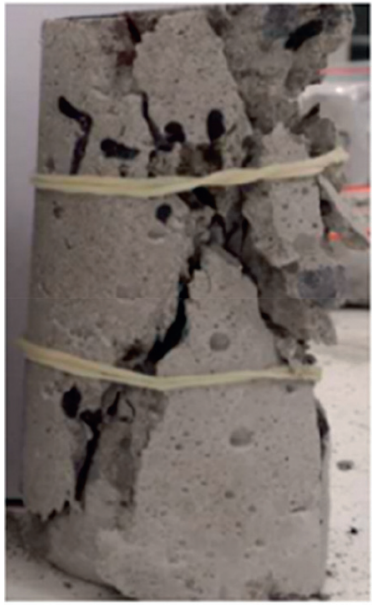

(d)

FIgURE 10: Failure pattern of specimens under the different water bath temperatures (drying and wetting cycles, 3 times). (a) Normal atmospheric temperature. (b) $40^{\circ} \mathrm{C}$. (c) $60^{\circ} \mathrm{C}$. (d) $80^{\circ} \mathrm{C}$.

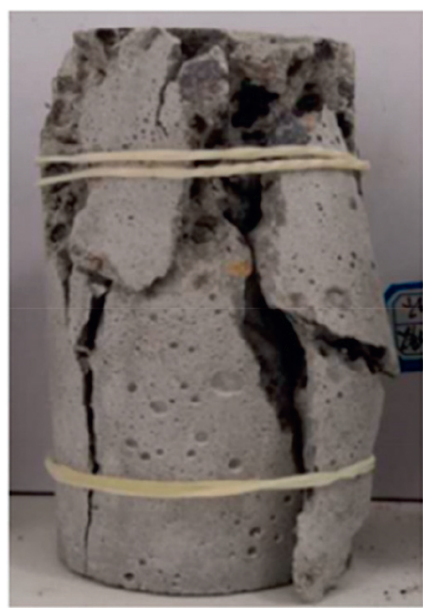

(a)

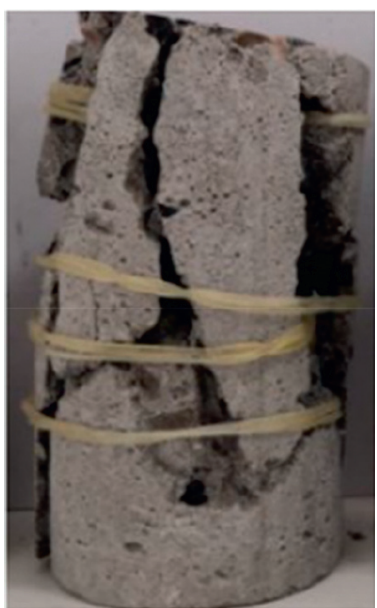

(b)

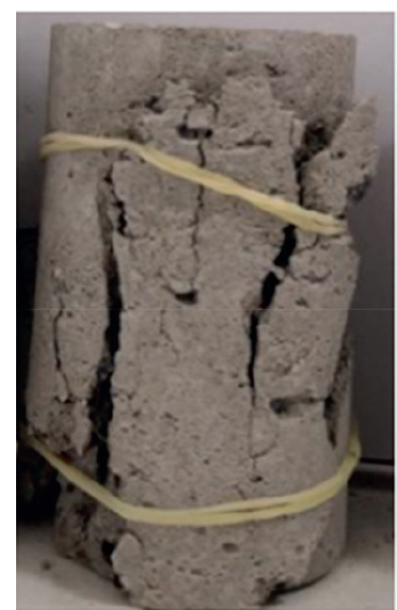

(c)

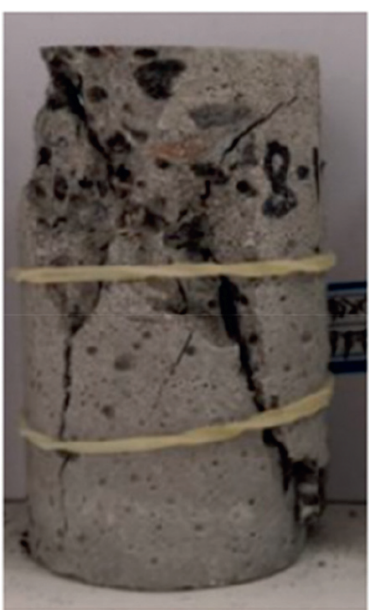

(d)

Figure 11: Failure pattern of specimens under different cycle times $\left(40^{\circ} \mathrm{C}\right)$. (a) Three times. (b) Seven times. (c) 14 times. (d) 28 times.

cycles, among which the specimen with cycling for 3 and 7 times has a greater crushing degree, while the crushing degree of the specimen with cycling for 28 times is small, but some parts of specimen are spalling. It is analyzed that this is caused by the dispersion and condensation of sample components under the action of the drying and wetting cycles. 


\section{Conclusion}

(1) Under normal temperature water bath, the creep deformation and axial creep strain of thermal insulation shotcrete specimens increase with the increasing times of the drying and wetting cycles, the deformation values after cycling for 28 times increase obviously, and the axial creep strain increases greatly at the early stage of cycle times.

(2) The results show that the axial steady creep rate of thermal insulation shotcrete increases nonlinearly with the increase of the drying and wetting cycles under different stress levels, and the value of axial steady creep strain rate is larger at the higher stress level, among which the average increase of $0-3$ times is the largest, and the maximum value is $92.57 \%$. The axial steady-state creep rate of thermal insulation shotcrete increases with the increase of water bath temperature after doing the drying and wetting cycles for 28 times, which indicates that the drying and wetting cycles will increase the axial steady-state creep rate of thermal insulation shotcrete under higher water bath temperature.

(3) The results show that the instantaneous deformation modulus of thermal insulation shotcrete decreases logarithmically with the increasing times of the drying and wetting cycles. The total degradation degree of average instantaneous deformation modulus increases gradually, but the stage deterioration degree between adjacent cycles decreases in turn.

(4) The fracture of thermal insulation shotcrete specimen in 3 cycles is mainly based on tensile, and shear failure occurs with the increase of immersion temperature. When the water bath temperature is $40^{\circ} \mathrm{C}$, the fragmentation degree of the specimen first increases and then decreases with the increasing times of the cycles.

\section{Data Availability}

The data used to support the findings of this study are available from the corresponding author upon request.

\section{Conflicts of Interest}

The authors declare that they have no conflicts of interest.

\section{References}

[1] B. Shi-Ke, Study on Utilization of Deep Geothermal Resources in Tang Kou Coal Mine, China University of Mining and technology, Beijing, China, 2018.

[2] Y. Yu-Biao, Research on thermal Damage Control Technology of Deep Mine in Zhangshuanglou Coal Mine, China University of Mining and Technology, Beijing, China, 2012.

[3] J.-R. Zhang and O. Xiao-Qiang, "Research idea for highperformance thermal insulation lightweight aggregate shotcrete in high geo-temperature tunnel," Concrete, vol. 323, no. 9, pp. 140-144, 2016.
[4] W.-J. Yao and J.-Y. Pang, "Research and application of new thermal insulation concrete shotcrete support technology," Journal of Yangtze River Academy of Sciences, vol. 34, no. 1, pp. 124-128, 2017.

[5] Q.-L. Wang and L. Xiao-Xiang, "Analysis on the relationship between water content and stability of surrounding rock in tertiary water rich silty fine sand layer of Taoshuping tunnel and Humaling tunnel," Modern Tunnel Technology, vol. 49, no. 4, pp. 1-5, 2012.

[6] D. Ma, H. Duan, X. Li, Z. Li, Z. Zhou, and T. Li, "Effects of seepage-induced erosion on nonlinear hydraulic properties of broken red sandstones," Tunnelling and Underground Space Technology, vol. 91, no. 9, Article ID 102993, 2019.

[7] D. Ma, H. Duan, J. Liu, X. Li, and Z. Zhou, "The role of gangue on the mitigation of mining-induced hazards and environmental pollution: an experimental investigation," The Science of the Total Environment, vol. 664, no. 5, pp. 436-448, 2019.

[8] D. Ma, J. Zhang, H. Duan et al., "Reutilization of gangue wastes in underground backfilling mining: o," Chemosphere, vol. 264, no. 2, Article ID 128400, 2021.

[9] X.-L. Cao, Resource Utilization Technology of High Temperature Heat Damage in Deep Mine of Sanhejian Mine, China University of Mining and Technology, Beijing, China, 2010.

[10] Z. Gao-wen, L. Jing-pei, H.-h. fan et al., "Effect of chloride on sulfate corrosion deterioration and diffusion of cast-in-situ concrete under dry wet cycle," Journal of Tongji University: Natural Science Edition, vol. 46, no. 12, pp. 1637-1645, 2018.

[11] L. Bei-xing, Q. Fang, and F. Peng, "Durability of high content admixture concrete semi immersed in sulfate solution," Journal of Harbin Engineering University, vol. 41, no. 6, p. 7, 2020.

[12] C. Wei-kang and Q.-f. Liu, "Numerical study on coupled transport of moisture and multi ions in concrete under dry wet alternation," Journal of Hydraulic Engineering, vol. 1-11, 2021.

[13] M.-H. Zhang and Y.-Y. sun, "Resistance to Cl- permeability of nano concrete under dry wet cycling," Journal of Harbin Institute of Technology, vol. 51, no. 8, pp. 167-176, 2019.

[14] L. Yao, S.-P. Yin, and L. V. Heng-Lin, "Interfacial properties of fiber reinforced concrete and existing concrete under chloride drying and wetting cycles," Journal of Central South University, vol. 27, no. 3, pp. 252-266, 2020.

[15] H. Xue-Qiang, S.-L. Zhan, Q. Xu et al., "Effect of dry wet cycling on chloride ion penetration resistance of concrete," Acta Composite Materials, vol. 37, no. 1, pp. 198-204, 2020.

[16] L. Jiang and N. Di-Tao, "Study on constitutive relation of concrete under sulfate attack and dry wet cycle," Journal of China University of Mining and Technology, vol. 46, no. 1, pp. 66-73, 2017.

[17] K.-f. Chen, Q. Hong-xia, P.-h. Wang et al., "Reliability evaluation of recycled concrete dry wet cycle based on NMR," Journal of Huazhong University of Science and Technology (Nature Science Edition), vol. 48, no. 7, pp. 88-92, 2020.

[18] L. Yue, Z. Guan, P. Geng et al., "Study on deterioration performance of early age concrete under sulfate and dry wet cycle," Concrete, vol. 359, no. 9, pp. 6-8, 2019.

[19] J. Shao-fei, E.-j. Cui, J. Wang et al., "Study on interfacial bonding performance of CFRP concrete under chloride dry wet cycle," Journal of Building Structures, vol. 1-11, 2021.

[20] L. Qiang, X. Li, K. Yang et al., "The long-term failure mechanisms of alkali-activated slag mortar exposed to wetdry cycles of sodium sulphate," Cement and Concrete Composites, vol. 116, Article ID 103893, 2020. 
[21] J.-J. Guo, P.-Q. Liu, C.-L. Wu, and K. Wang, "Effect of dry-wet cycle periods on properties of concrete under sulfate attack," Applied Sciences, vol. 11, no. 2, p. 888, 2021.

[22] A. Dehestani, M. Hosseini, and A. Taleb Beydokhti, "Effect of wetting-drying cycles on mode I and mode II fracture toughness of cement mortar and concrete," Theoretical and Applied Fracture Mechanics, vol. 106, Article ID 102448, 2020.

[23] L. Da-qing, C. Liang-liang, J.-W. Gong et al., "Study on the relationship between compressive strength and splitting tensile strength of recycled concrete under sulfate dry wet cycle," Water Resources and Hydropower Technology, vol. 49, no. 4, pp. 188-194, 2018.

[24] J. Cao, L.-F. Liu, Z. Han et al., "Experimental study on creep of fly ash concrete under dry wet cycling," Journal of Nanchang Institute of Engineering, vol. 36, no. 4, 2017.

[25] L. Han-Hu, L. Xiu-Han, Z.-q. Jiang et al., "Influence of underground water temperature on prediction of mine water inflow," China Coal Geology, vol. 26, no. 7, pp. 42-44, 2014.

[26] Ministry of Housing and Urban Rural Development of the People's Republic of China, JGJ/T372-2016, Technical Specification For Application Of Shotcrete, China Construction Industry Press, Beijing, China, 2016.

[27] Ministry of Construction of the People's Republic of China, GB/T50081-2002, Test Method Standard for Mechanical Properties of Ordinary concrete, China Construction Industry Press, Beijing, China, 2003.

[28] Q.-y. Ma, Y. Pei-Yang, and P. U. Yuan, "Experimental study on the influence of dry wet cycle on creep characteristics of deep siltstone," Journal of Rock Mechanics and Engineering, vol. 37, no. 3, pp. 593-600, 2018.

[29] H.-F. Deng, Z.-Y. Xiao, L. Jian-Lin et al., "Experimental study on strength degradation of damaged sandstone under water rock interaction," Journal of Rock Mechanics and Engineering, vol. 34, no. S1, pp. 2690-2698, 2015. 